\title{
Brief
}

\section{Video-assisted thoracoscopic completion pneumonectomy for a second primary cancer: $A$ case report}

Ryoichi Nakanishi, MD, PhD, Ayako Hirai, MD, Toshihiro Yamashita, MD, and Soichi Oka, MD, Kitakyushu, Japan

From the Department of Thoracic Surgery, Shin-Kokura Hospital, Federation of National Public Service, Personnel Mutual Aid Associations, Kitakyushu, Japan.

Received for publication Aug 17, 2007; accepted for publication Nov 20, 2007.

Address for reprints: Ryoichi Nakanishi, $\mathrm{MD}, \mathrm{PhD}$, Chief, Department of Thoracic Surgery, Shin-Kokura Hospital, Federation of National Public Service, Personnel Mutual Aid Associations, Kanada 1-3-1, Kokurakita-ku, Kitakyushu, 803-8505, Japan (E-mail: ryoichi@med.uoeh-u.ac.jp).

J Thorac Cardiovasc Surg 2008;135:945-6 $0022-5223 / \$ 34.00$

Copyright $\odot 2008$ by The American Association for Thoracic Surgery

doi:10.1016/j.jtcvs.2007.11.043

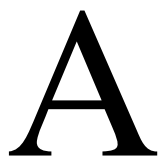

lthough completion pneumonectomy offers a chance for a cure in patients with second primary lung cancer, it is also associated with high morbidity and mortality. ${ }^{1}$ For high-risk patients, this surgical procedure may be contraindicated. Landreneau and associates have demonstrated that video-assisted thoracic surgery (VATS) has a similar efficacy to open thoracotomy while providing the benefits of a decreased pain-related morbidity. ${ }^{2}$ VATS therefore seems preferable for high-risk patients. This report describes a successful completion pneumonectomy for a second primary lung cancer that was performed with a VATS approach to minimize postoperative complications in a high-risk patient with advanced age and a poor pulmonary reserve.

\section{Clinical Summary}

An 80-year-old woman who had at 77 years of age undergone bilateral pulmonary resection by VATS, including a left lower lobectomy with a mediastinal lymphadenectomy and a right anterior basal segmentectomy for synchronous tumors, was admitted after a lung abnormality was observed on chest imaging (Figure 1). The final pathologic classification and staging of the left tumor showed a squamous cell carcinoma and T1N0M0, although the right tumor was a granuloma.

Adenocarcinoma was diagnosed after a computed tomographically guided percutaneous needle biopsy. The clinical stage was determined as T2N0M0, stage 1B, with brain magnetic resonance, bone scintigraphy, and body computed tomography. Results of laboratory examinations were unremarkable. A spirometric examination revealed a forced vital capacity of $2.43 \mathrm{~L}$ and a forced expiratory volume in 1 second of $1.32 \mathrm{~L}$. The postoperative forced vital capacity and forced expiratory volume in 1 second predicted on the basis of quantitative perfusion lung scans were $1.54 \mathrm{~L}\left(1.00 \mathrm{~L} / \mathrm{m}^{2}\right)$ and $0.84 \mathrm{~L}\left(0.54 \mathrm{~L} / \mathrm{m}^{2}\right)$, respectively. Although the predicted postoperative forced expiratory volume in 1 second did not meet the indications for surgery, ${ }^{3}$ an operation was planned because the hemodynamic studies of a temporary occlusion of the left pulmonary artery were favorable.

General anesthesia was induced with a dual-lumen endotracheal tube in place, and the patient was placed in a right lateral decubitus position. A small utility thoracotomy, $7 \mathrm{~cm}$ in length from the anterior edge of the latissimus dorsi muscle to the anterior axillary line, was made in the third intercostal space. Three additional port sites were then placed in the seventh intercostal spaces in the anterior and posterior axillary lines and in the auscultatory triangle. VATS exploration demonstrated dense adhesions around the hilum, although there was little obliteration of the pleural space.

An opening the pericardium was created endoscopically because the hilar adhesions were hard enough to dissect extrapericardially. After separation of Botallo's duct, the pulmonary artery was carefully dissected from the outside of the pericardium and from the inside with Marshall's fold as a marker (Figure 2). The pulmonary artery was then stapled with an endoscopic linear stapler with the knife removed and was divided. The pulmonary veins were treated intrapericardially in the same manner, because the stump of the inferior vein could not be identified. After removal of the subcarinal nodes, the main stem bronchus was divided with a $30-\mathrm{mm}$ linear stapler. The bronchial stump, with additional sutures at both ends, was not reinforced with any viable tissue. A systematic dissection of the upper mediastinal nodes was then performed, 


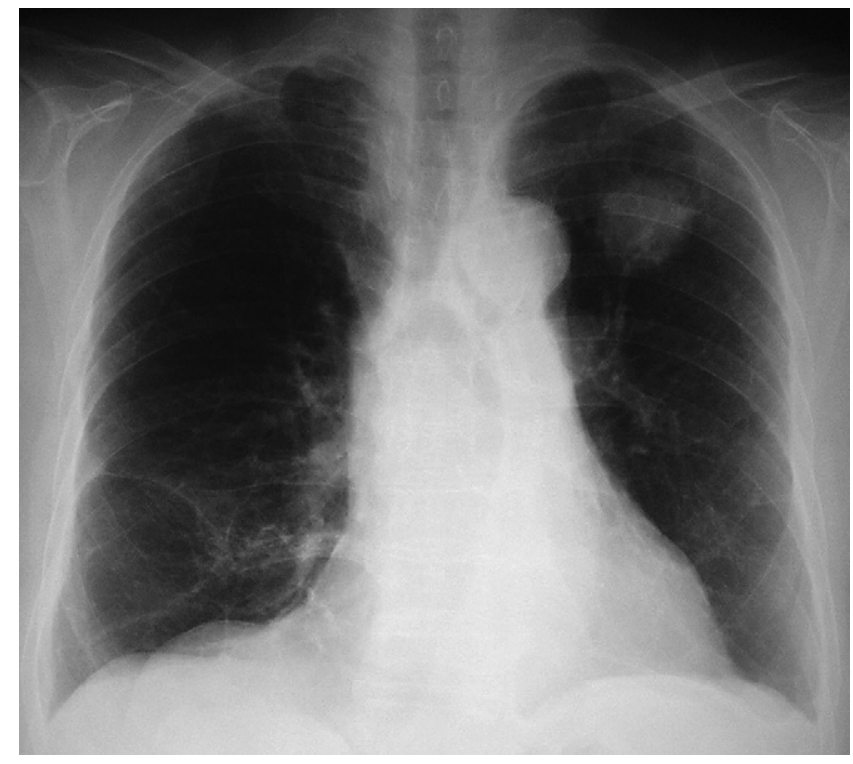

Figure 1. Chest radiogram reveals nodular opacity $\mathbf{4 0} \mathrm{mm}$ in diameter in left upper lung field.

despite the presence of dense adhesions. The operative time was 350 minutes, and the bleeding volume was $241 \mathrm{~mL}$. Blood transfusion was not required during either the surgery or the postoperative course. There were no intraoperative problems, and the patient had an uneventful recovery. Her chest tube was removed on postoperative day 2 . She was discharged on postoperative day 14 . The final staging of the tumor showed T2NOM0. The patient was alive without signs of recurrence as of 18 months after the operation.

\section{Discussion}

There are no previous reports of a VATS completion pneumonectomy. For conventional thoracotomy, high operative mortality has often been reported, closely associated with advanced age and serious complications, including bronchopleural fistula. ${ }^{1,4}$ In this operation, the factors that suggested the potential success were a previous surgery by VATS without obliteration of the pleural space and a leftsided operation, reducing the risk of bronchopleural fistula. ${ }^{4,5}$

Primary intrapericardial vascular control is the key to a safe operation. Vascular control with VATS is technically feasible and safe,

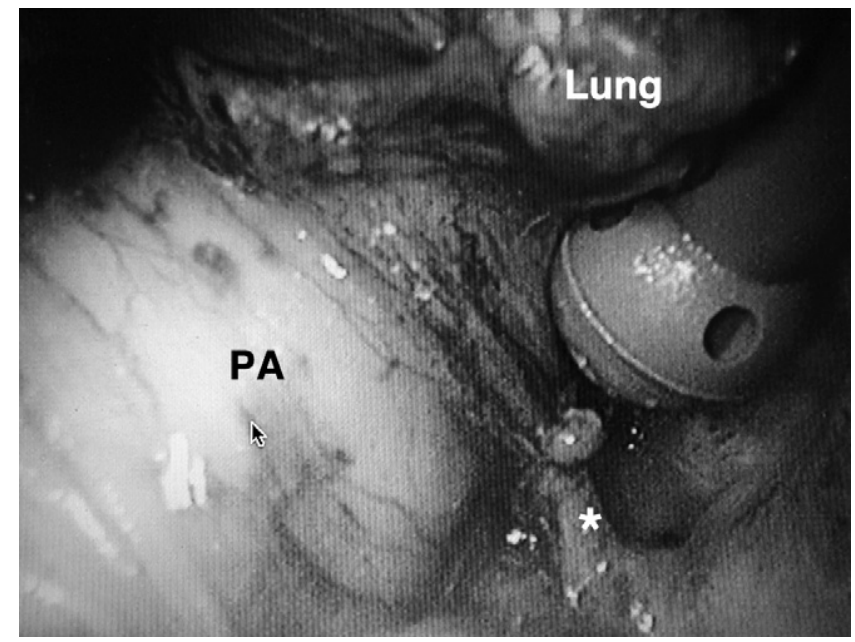

Figure 2. Operative photograph. Asterisk indicates Marshall's fold in pericardium. PA, Pulmonary artery.

because VATS can magnify the visual image of the posterior wall of the vessel hidden from surgeon's eye.

VATS offers the surgeon and patient an alternative method of treatment for a second primary lung cancer. This method avoids the morbidity of a conventional thoracotomy for the patient and also allows a quicker recovery.

\section{References}

1. Miller DL, Deschamps C, Jenkins GD, Bernard A, Allen MS, Pairolero PC. Completion pneumonectomy: factors affecting operative mortality and cardiopulmonary morbidity. Ann Thorac Surg. 2002;74: 876-84.

2. Landreneau RJ, Hazelrigg SR, Mack MJ, Dowling RD, Burke D, Gavlick J, et al. Postoperative pain-related morbidity: video-assisted thoracic surgery versus thoracotomy. Ann Thorac Surg. 1993;56:1285-9.

3. Uramoto $\mathrm{H}$, Nakanishi $\mathrm{R}$, Fujino $\mathrm{Y}$, Imoto $\mathrm{H}$, Takenoyama $\mathrm{M}$, Yoshimatsu T, et al. Prediction of pulmonary complications after a lobectomy in patients with non-small cell lung cancer. Thorax. 2001;56:59-61.

4. Fujimoto T, Zaboura G, Fechner S, Hillejan L, Schröder T, Marra A, et al. Completion pneumonectomy: current indications, complications, and results. J Thorac Cardiovasc Surg. 2001;121:484-90.

5. Guggino G, Doddoli C, Barlesi F, Acri P, Chetaille B, Thomas P, et al. Completion pneumonectomy in cancer patients: experience with 55 cases. Eur J Cardiothorac Surg. 2004;25:449-55. 